V.Yu. Rozov, V.S. Grinchenko, O.O. Tkachenko

\title{
CALCULATION OF MAGNETIC FIELD OF THREE-PHASE CABLE LINES WITH TWO-POINT BONDED CABLE SHIELDS COVERED BY FERROMAGNETIC CORES
}

In this paper we obtain compact expressions for the magnetic field shielding factor of a high-voltage three-phase cable line consisting of single-core cables with two-point bonded cable shields and ferromagnetic cores installed. To obtain these expressions we develop the analytical model of the cable line. Following assumptions are made to develop the model: the current distribution in each cable shield is uniform, cylindrical ferromagnetic cores covering the cables are not magnetized to saturation and their magnetic permeability is constant, each of the ferromagnetic cores is magnetized only by the core current and the shield current of the cable that it covers, the magnetic field inside ferromagnetic cores is axisymmetric, the magnetic field is planeparallel over the entire cable line. We consider common cases of flat and trefoil cable lines. The proposed expressions for the magnetic field shielding factor are verified experimentally. The physical model is made of three cables of the type $\mathrm{NA2XSF(L)2Y-}$ $1101 \times 240 / 70$. It is shown that the difference between numerical simulation results and experimental data lays within $15 \%$. References 11, figures 3.

Key words: cable line, shield of cable, magnetic field, bonded shields, ferromagnetic core.

Получены компактные соотночения для расчета эффективности экранирования магнитного поля высоковольтной трехфазной кабельной линии, состоящей из одножильных кабелей, которые охвачены ферромагнитными сердечниками, при двустороннем замыкании собственных экранов. Рассмотрены кабельные линии с укладкой кабелей треугольником и в плоскости. Предложенные соотночения для расчета эффективности экранирования магнитного поля верифицированы экспериментально. Библ. 11, рис. 3.

Ключевые слова: кабельная линия, экран кабеля, магнитное поле, двустороннее заземление, ферромагнитный сердечник.

Introduction. Compliance with the maximum permissible levels of magnetic induction is mandatory when laying high-voltage cable lines (CL). In Ukraine, the maximum permissible level of magnetic induction inside living quarters located near the $\mathrm{CL}$ is $0.5 \mu \mathrm{T}$ [1, p. 277]. As the distance between single-core cables with cross-linked polyethylene insulation increases, the value of the magnetic induction of the $\mathrm{CL}$ can significantly exceed the permissible level [1, p. 285].

Electromagnetic, magnetostatic and contoured shields are used to reduce the magnetic field (MF) of CLs [2-4]. Another approach to reducing the MF of the CL which does not require the installation of additional screens, is the two-way closure of the CL cable shields by two-way grounding at both ends of the shielding zone [5-7]. In this case, the MF shielding efficiency is $1.5 \div 2.5$ [5], which is not always sufficient for the normalization of the MF of the CL. A further increase in MF shielding efficiency can be achieved by strengthening the magnetic coupling between the cores and shields of the CL cables [8]. To do this, each of the cables (Fig. 1) is covered by a ferromagnetic core (FC) made of laminated electrical steel.

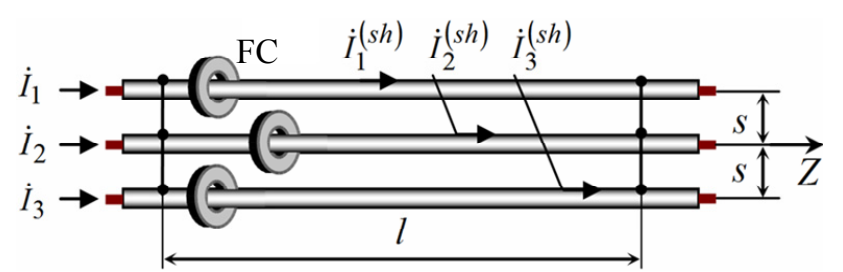

Fig. 1. A three-phase CL with installed FC
In [8], the dependence of the shielding efficiency of the MF on the number of PSs installed on each of the cables was experimentally investigated. The measurements made on the physical model of the CL confirmed the possibility of 2 to 4 times increase in shielding efficiency in comparison with the traditional two-sided closure of cable screens. However, the relations proposed in [8] for calculating the shielding efficiency of a magnetic field with a ferromagnetic core need to be refined.

The goal of the work is obtaining theoretically grounded relationships for calculating the shielding efficiency of the magnetic field of a three-phase cable line with two-sided closed shields and ferromagnetic cores installed on the cables.

The effectiveness of shielding the MF of the $C L$ when laying cables in a triangle. The effectiveness of shielding MF is defined as the ratio of the effective value of magnetic induction to two-sided closure of the cable shields to the effective value of the magnetic induction after closing the cable shields [9]:

$$
S F=\left|\dot{\vec{B}}_{0}\right| /|\dot{\vec{B}}|
$$

We assume that the cables are straight (or the radius of their curvature can be neglected) and are parallel to each other. In the case when the cable shields are open, the MF of the CL is determined only by the currents in the veins. If the $X$ axis is parallel to the ground level and perpendicular to the cable axes, and the $Y$ axis is directed upwards, the complex amplitude of the magnetic flux density at the point with the $(x, y)$ coordinates is [9]: 


$$
\begin{array}{r}
\dot{\vec{B}}_{0}=\frac{\mu_{0}}{2 \pi} \cdot \sum_{k=1}^{3} \dot{I}_{k} \cdot\left(-\frac{y-y_{k}}{\left(x-x_{k}\right)^{2}+\left(y-y_{k}\right)^{2}} \cdot \vec{e}_{x}+\right. \\
\left.+\frac{x-x_{k}}{\left(x-x_{k}\right)^{2}+\left(y-y_{k}\right)^{2}} \cdot \vec{e}_{y}\right),
\end{array}
$$

where $k=\overline{1,3}$ is the cable number; $\dot{I}_{k}$ is the complex current amplitude in the core of the $k$-th cable; $\vec{e}_{x}, \vec{e}_{y}$ are the orts of the Cartesian coordinate system; $\left(x_{k}, y_{k}\right)$ are the axes coordinates of the $k$-th cable; $\mu_{0}=4 \pi \cdot 10^{-7} \mathrm{H} / \mathrm{m}$ is the magnetic constant.

For two-sided closure of shields, the complex amplitude of the magnetic flux density is [9]:

$$
\begin{aligned}
\dot{\vec{B}}=\frac{\mu_{0}}{2 \pi} & \cdot \sum_{k=1}^{3}\left(\dot{I}_{k}+\dot{I}_{k}^{(s h)}\right) \times \\
& \times\left(-\frac{y-y_{k}}{\left(x-x_{k}\right)^{2}+\left(y-y_{k}\right)^{2}} \cdot \vec{e}_{x}+\right. \\
& \left.+\frac{x-x_{k}}{\left(x-x_{k}\right)^{2}+\left(y-y_{k}\right)^{2}} \cdot \vec{e}_{y}\right),
\end{aligned}
$$

where $\dot{I}_{k}^{(s h)}$ is the complex current amplitude in the shield of the $k$-th cable.

As can be seen from (1)-(3), in order to calculate the shielding efficiency, it is necessary to determine the currents in the cable shields in the presence of ferromagnetic cores.

Consider a three-phase CL with a triangular laying of cables covered by cylindrical ferromagnetic cores (see Fig. 1).

Since the cable screens are closed at both ends of the CL, the first Kirchhoff law of is satisfied for the currents induced in them:

$$
\dot{I}_{1}^{(s h)}+\dot{I}_{2}^{(s h)}+\dot{I}_{3}^{(s h)}=0 .
$$

We consider the contour formed by shields of the $1 \mathrm{st}$ and the 2nd cables, and a circuit formed by shields of the 2nd and the 3rd cables. EMFs induced in circuits are determined by magnetic fluxes that permeate them $[10$, p. 59]. Based on the Ohm law in complex form and the law of electromagnetic induction, we write the following relationships for each of the circuits:

$$
\begin{aligned}
& \left(\dot{I}_{1}^{(s h)}-\dot{I}_{2}^{(s h)}\right) \cdot R^{*}=-j \omega \cdot\left(\dot{\Psi}_{1}^{(1,2)}-\dot{\Psi}_{2}^{(1,2)}\right), \\
& \left(\dot{I}_{2}^{(s h)}-\dot{I}_{3}^{(s h)}\right) \cdot R^{*}=-j \omega \cdot\left(\dot{\Psi}_{2}^{(2,3)}-\dot{\Psi}_{3}^{(2,3)}\right),
\end{aligned}
$$

where $j$ is the imaginary unit; $\omega=2 \pi \cdot 50 \mathrm{~s}^{-1}$ is the angular frequency of current; $R^{*}$ is the active resistance of the unit of the cable shield length, $\Omega / \mathrm{m} ; \dot{\Psi}_{k}^{(m, n)} \equiv \dot{\Psi}_{k}^{(n, m)}$ is the complex amplitude of the total flux of the magnetic field which is created by the currents of the core and shield of the $k$-th cable and penetrates the circuit formed by the shields of cables with numbers $m$ and $n$.

For the triangle CL because of axial symmetry $\dot{\Psi}_{k}^{(m, n)}=0$, when $k \neq m$ and $k \neq n$.
For the calculation of $\dot{\Psi}_{k}^{(k, n)}$ we take the following assumptions:

- the distribution of the induced current in the screen of each cable is uniform;

- cylindrical FCs covering cables are not magnetized to saturation, and their magnetic permeability is constant and equal to $\mu$;

- each of the FC is magnetized by the currents of the vein and shield of only the cable that it covers, and the $\mathrm{MF}$ inside the $\mathrm{FC}$ is axisymmetric;

- over the entire length of the CL, the MF is planeparallel.

Then the complex amplitude of the magnetic induction of the field created by the currents of the core and the screen of the $k$-th cable has only an angular component with respect to the axis of the $k$-th cable and is equal $\mu \mu_{0}\left(\dot{I}_{k}^{(s h)}+\dot{I}_{k}\right) / 2 \pi r$ inside the FC and $\mu_{0}\left(\dot{I}_{k}^{(s h)}+\dot{I}_{k}\right) / 2 \pi r$ outside the FC. By dividing the currents in cable shields with numbers $k$ and $n$ into elementary tubes of an infinitesimally small cross section $[11,8]$, and integrating over all possible contours formed by these tubes, we find:

$$
\begin{aligned}
\dot{\Psi}_{k}^{(k, n)} & =\frac{\mu_{0}\left(\dot{I}_{k}^{(s h)}+\dot{I}_{k}\right)}{2 \pi} \cdot \ln \frac{s}{r}+ \\
& +\frac{l_{\text {core }}}{l} \cdot \frac{(\mu-1) \mu_{0}\left(\dot{I}_{k}^{(s h)}+\dot{I}_{k}\right)}{2 \pi} \cdot \ln \frac{r_{1}}{r_{2}},
\end{aligned}
$$

where $s$ is the distance between cable axes, $\mathrm{m} ; r$ is the shield radius, $\mathrm{m}$; $l$ is the length of the $\mathrm{CL}$ shielded part, $\mathrm{m}$; $l_{\text {core }}$ is the total length of the FC installed on each of cables, $\mathrm{m} ; r_{1}$ and $r_{2}$ are the external and internal $\mathrm{FC}$ radius, respectively, $\mathrm{m}$;

Expressions (4)-(5) form a system of three equations with respect to $\dot{I}_{1}^{(s h)}, \dot{I}_{2}^{(s h)}$ and $\dot{I}_{3}^{(s h)}$. Substituting (6) we find its solution:

$$
\dot{I}_{k}^{(s h)}=-\dot{I}_{k} \frac{j \omega M^{*}}{R^{*}+j \omega M^{*}}=\alpha \cdot \dot{I}_{k}, \alpha=\frac{-j \omega M^{*}}{R^{*}+j \omega M^{*}},
$$

where $M^{*}=\frac{\mu_{0}}{2 \pi} \cdot \ln \frac{s}{r}+\frac{l_{\text {core }}}{l} \cdot \frac{(\mu-1) \mu_{0}}{2 \pi} \cdot \ln \frac{r_{1}}{r_{2}} \quad$ is the specific equivalent inductance of the shield covered by the core, $\mathrm{H} / \mathrm{m}$.

Substituting (7) in (1)-(3) we obtain the final relation for the shielding efficiency in case of triangular cable laying:

$$
S F_{\text {trefoil }}=\frac{1}{|1+\alpha|}=\left|\begin{array}{l}
1+j \cdot \frac{\mu_{0} \omega}{2 \pi R^{*}} \cdot \ln \frac{s}{r}+ \\
+j \cdot \frac{l_{\text {core }}}{l} \cdot \frac{(\mu-1) \mu_{0} \omega}{2 \pi R^{*}} \cdot \ln \frac{r_{1}}{r_{2}}
\end{array}\right| .
$$

The effectiveness of the shielding of the MF of the CL when laying cables in the plane. In [9], the authors showed that for the analysis of the MF of the CL with a 
plane cable laying, it is sufficient to consider the dipole component of the field, and a simplified relation for calculating the shielding efficiency when laying cables in the plane can be obtained by substituting $s \rightarrow 2 \cdot s$ into the ratio for shielding efficiency for laying cables in a triangle. Therefore, when laying cables in the plane

$$
S F_{\text {flat }}=\left|\begin{array}{l}
1+j \cdot \frac{\mu_{0} \omega}{2 \pi R^{*}} \cdot \ln \frac{2 s}{r}+ \\
+j \cdot \frac{l_{\text {core }}}{l} \cdot \frac{(\mu-1) \mu_{0} \omega}{2 \pi R^{*}} \cdot \ln \frac{r_{1}}{r_{2}}
\end{array}\right| .
$$

To verify (9), we use the results of experimental studies performed by the authors of [8]. The research was carried out on the physical model of the CL. The model is made of NA2XSF(L)2Y-110 $1 \times 240 / 70$ cables of length $l=10 \mathrm{~m}$ (Fig. 2). The active resistance of the cable screen length unit is $R^{*}=0.29 \times 10^{-3} \Omega / \mathrm{m}$. The distance between the axes of the cables is $0.2 \mathrm{~m}$. The current value in the conductors of the cables is $95 \mathrm{~A}$.

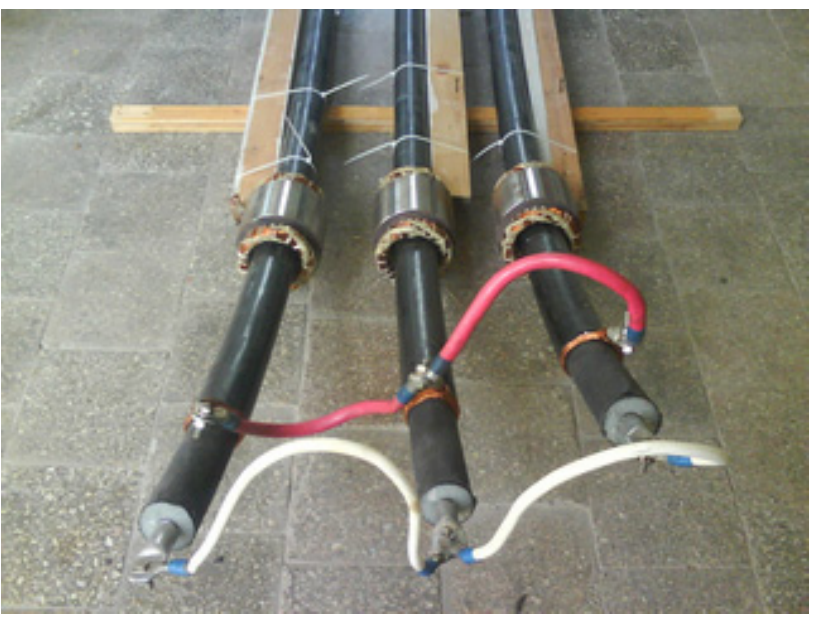

Fig. 2. Physical layout of the CL

As FC, stator cores of asynchronous electric motors were used, which are made of electrically bonded steel. The magnetic permeability of cores $\mu=3000$ was determined experimentally. The outer radius of the core $r_{1}=65 \mathrm{~mm}$, the inner radius $r_{2}=50 \mathrm{~mm}$. The length of one core is $100 \mathrm{~mm}$.

The number of FCs installed on each cable ranged from 0 to 3. Accordingly, the total length of the FC cores installed on each of the cables during the experimental studies was $0,100 \mathrm{~mm}, 200 \mathrm{~mm}$ and $300 \mathrm{~mm}$.

Measurement of magnetic induction was performed using a three-component EMF-828 magnetometer.

Fig. 3 shows: the curve of the shielding efficiency versus the total length of the FC installed on each of the cables constructed according to (9) and the points corresponding to the results of measuring the shielding efficiency in the FC layout. As can be seen from the figure, in the absence of $\mathrm{FC}$ the results of calculation and measurements coincide. When the FC is used, the deviation of the experimental data from the calculation results does not exceed $15 \%$.
The ratio (8) in comparison with (9) was obtained under milder assumptions. Therefore, it can be argued that the error of application (8) also does not exceed $15 \%$.

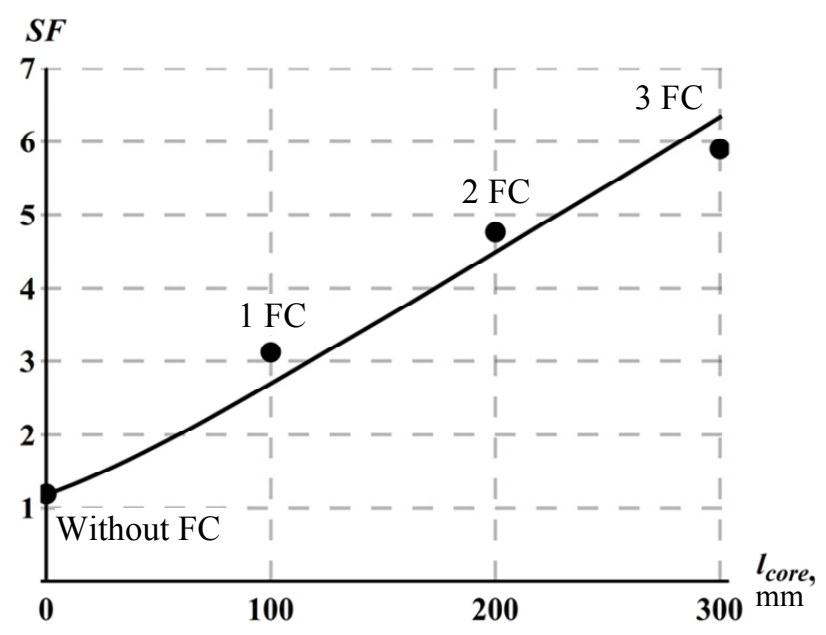

Fig. 3. Dependence of the shielding efficiency of the MF of the $\mathrm{CL}$ on the total FC

\section{Conclusions.}

1. Theoretically grounded relationships for the engineering calculation of the shielding efficiency of the magnetic field of the cable line for cases of laying cables in the plane and a triangle for two-sided closure of the cable shields covered by ferromagnetic cores were obtained for the first time.

2. Experimental investigations carried out on the physical layout of the cable line confirmed the correctness of the obtained calculated relationships, the error of which does not exceed $15 \%$ if the distance between the cables is three times larger than the outer radius of the ferromagnetic cores.

\section{REFERENCES}

1. Pravila ulashtuvannya electroustanovok [Electrical installation regulations]. 5th ed. Kharkiv, Minenergovugillya of Ukraine, 2014. 793 p. (Ukr).

2. Rezinkina M.M., Grinchenko V.S. Underground busbars magnetic field mitigation with the help of electro-magnetic shields, consisted of U-shaped elements. Bulletin of NTU «KhPI», 2012, no.49, pp. 73-78. (Rus).

3. Canova A., Giaccone L. A novel technology for magneticfield mitigation: High magnetic coupling passive loop. IEEE Transactions on Power Delivery, 2011, vol.26, no.3, pp. 16251633. doi: 10.1109/tpwrd.2010.2099671.

4. De Wulf M., Wouters P., Sergean P., Dupre' L., Hoferlin E., Jacobs S., Harlet P. Electromagnetic shielding of high-voltage cables. Journal of Magnetism and Magnetic Materials, 2007, vol.316, no.2, pp. 908-911. doi: 10.1016/j.jmmm.2007.03.137. 5. Rozov V.Yu., Kvytsynskyi A.A., Dobrodeyev P.N., Grinchenko V.S., Erisov A.V. and Tkachenko O.O. Study of the magnetic field of three phase lines of single core power cables with two-end bonding of their shields. Electrical engineering \& electromechanics, 2015, no.4, pp. 56-61. (Rus). doi: 10.20998/2074-272X.2015.4.11.

6. SOU-N MEV 40.1-37471933-49:2011.2. Proektuvannia kabelnykh linii napruhoiu do $330 \mathrm{kV}$. Nastanova [Design of cable lines with voltage up to $330 \mathrm{kV}$. Guidance]. Kyiv, Minenergovugillya of Ukraine Publ., 2017, 139 p. (Ukr). 
7. SOU-N EE 20.179:2008. Rozrakhunok elektrychnoho $i$ mahnitnoho poliv linii elektroperedavannia. Metodyka [Calculation of the electric and magnetic fields of power line. Method]. Kyiv, Minenergovugillya of Ukraine Publ., 2016, 34 p. (Ukr).

8. Rozov V.Yu., Dobrodeyev P.N., Erisov A.V., Tkachenko A.O. Increasing the efficiency of contour shielding of the magnetic field of high-voltage cable lines. Tekhnichna Elektrodynamika, 2016, no.4, pp. 5-7. (Rus).

9. Rozov V.Yu., Tkachenko O.O., Erisov A.V. and Grinchenko V.S. Analytical calculation of magnetic field of three-phase cable lines with two-point bonded shields. Tekhnichna Elektrodynamika, 2017, no.2, pp. 13-18 (Rus).

10. Demirchian K.S., Neiman L.R., Korovkin N.V., Chechurin V.L. Teoreticheskie osnovy elektrotekhniki: V 3-kh t. Uchebnik dlia vuzov. Tom 1 [Theoretical bases of electrical engineering. In 3 vols. Vol.1]. St. Petersburg, Piter Publ, 2003. 463 p. (Rus).
11. Kalantarov P.L., Tseytlin L.A. Raschet induktivnostey [Inductance calculations]. Leningrad, Energoatomizdat Publ., 1986. 488 p. (Rus).

Received 07.08.2017

V.Yu. Rozov ${ }^{1}$, Doctor of Technical Science, Corresponding member of NAS of Ukraine,

V.S. Grinchenko ${ }^{1}$, Candidate of Technical Science,

O.O. Tkachenko ${ }^{1}$, Postgraduate Student,

${ }^{1}$ State Institution «Institute of Technical Problems of Magnetism of the NAS of Ukraine», 19, Industrialna Str., Kharkiv, 61106, Ukraine, phone +380572992162 ,

e-mail: vsgrinchenko@gmail.com

\section{How to cite this article:}

Rozov V.Yu., Grinchenko V.S., Tkachenko O.O. Calculation of magnetic field of three-phase cable lines with twopoint bonded cable shields covered by ferromagnetic cores. Electrical engineering \& electromechanics, 2017, no.5, pp. 41-44. doi: 10.20998/2074-272X.2017.5.06. 